\title{
Analitika Data Dalam Pengelolaan Keuangan Negara: Use Case Data Dasar Dana Alokasi Umum
}

\author{
Beta Andri Anggiano Uliansyah ${ }^{1 *}$, Agung Darono² ${ }^{2}$ Febrian $^{3}$ \\ ${ }^{1}$ Jurusan Manajemen Keuangan, Politeknik Keuangan Negara STAN, Tangerang Selatan, Banten \\ ${ }^{2}$ Kementerian Keuangan Republik Indonesia, DKI Jakarta \\ ${ }^{3}$ Jurusan Perpajakan, Politeknik Keuangan Negara STAN, Tangerang Selatan, Banten \\ Email: ${ }^{1 *}$ beta.uliansyah@ @knstan.ac.id, ${ }^{2}$ agungdarono@ kemenkeu.go.id, ${ }^{3}$ febrian@ $@$ pknstan.ac.id
}

(Naskah masuk: 31 Jan 2021, direvisi: 1 Jul 2021, 13 Jul 2021, diterima: 15 Jul 2021)

\begin{abstract}
Abstrak
Analitika data keuangan negara merupakan sekumpulan kerangka konsepsual yang digunakan untuk mengidentifikasi, mengekstraksi, dan mendapatkan pola atau anomali tertentu dari berbagai data keuangan negara untuk selanjutnya dapat disajikan dalam bentuk wawasan (insights), visualisasi ataupun model yang diharapkan dapat membantu pengambilan keputusan yang berkaitan dengan berbagai fungsi dan bidang pengelolaan keuangan negara. Penelitian ini dengan menggunakan rancangan penelitian deskriptif kualitatif menjelaskan bagaimana analitika data keuangan negara dapat dilaksanakan dengan menggunakan use case data dasar Dana Alokasi Umum (DAU) yang telah tersedia dan dapat diakses secara bebas oleh publik melalui situs web Kementerian Keuangan. Kajian ini menggunakan kombinasi beberapa paket perangkat lunak dan teknik analisis data untuk menyajikan berbagai insights yang dapat disajikan dari data yang telah tersedia tersebut. Penelitian ini dengan use case yang ada menemukan bahwa data keuangan negara telah disajikan dengan struktur data standar relatif memudahkan para pihak yang ingin menggunakan data tersebut untuk berbagai kepentingan. Rekomendasi kebijakan yang diajukan berdasarkan hasil kajian ini adalah: (1) data yang disediakan dapat mencakup seluruh data yang berkaitan dengan pengelolaan keuangan negara; (2) data disediakan dalam struktur standar sehingga memudahkan pengguna yang membutuhkan data tersebut. Untuk cakupan organisasi pemerintahan dalam skala yang lebih besar, penelitian ini merekomendasikan agar setiap instansi pemerintah dapat menyediakan data operasionalnya dengan struktur data yang mudah untuk diolah kembali sehingga memungkinkan data tersebut digunakan untuk kepentingan publik yang lebih luas.
\end{abstract}

Kata Kunci: Analisis, Data, Keuangan, Negara.

\section{Data Analytics in State Finance Management: Use Case of General Allocation Fund}

\begin{abstract}
Government financial data analytics is a bunch of concepts that are used to identify, extract, and obtain certain patterns or anomalies from various government financial data which then could provide some insights in the form of visualizations or models. This research uses descriptive qualitative research that explains the analytics of state financial data can be done using basic case data of the "Dana Alokasi Umum (DAU)", i.e. general allocation fund transferred from central to subnational government, which has been available and can be accessed by the public through the Indonesian Ministry of Finance's website. This study uses a combination of several software packages and data analysis techniques to present various insights that can be presented from the data that is already available. This study uses a case that finds state financial data provided with a standard data structure that makes it easy for those who want to use the data for various purposes. The policy recommendations proposed based on the results of this study are: (1) the data provided can complement all data relating to the management of the financial state; (2) data provided in a standard structure so as to enable users who need the data. To support government organizations on a larger scale, this study asks that each government be able to provide operational data with data structures that are easy to reprocess to facilitate data used for the wider community.
\end{abstract}

Keywords: Anaysis, Data, Finances, State. 


\section{PENDAHULUAN}

Undang-Undang Nomor 15 Tahun 2004 tentang Keuangan Negara (UU KN) mendefinisikan pengelolaan keuangan negara sebagai keseluruhan kegiatan pejabat pengelola keuangan negara sesuai dengan kedudukan dan kewenangannya, yang meliputi berbagai fungsi dan bidang. Dari sisi fungsi meliputi: perencanaan, pelaksanaan, pengawasan, dan pertanggungjawaban. Sementara itu dari sisi bidang mencakup perpajakan, anggaran, perbendaharaan, dana transfer ke pemerintah daerah, aset, hingga pembiayaan negara. Cakupan pekerjaan pengelolaan keuangan negara yang sangat luas dan cenderung kompleks tersebut tentunya memerlukan dukungan manajemen data dan teknologi informasi dan komunikasi yang komprehensif [1]-[6]. Salah satu dukungan dari sisi ini adalah kemampuan analisis data yang terkait dengan data tersebut juga sangat luas cakupannya, dari yang bersifat makro untuk perencanaan APBN sampai dengan data mikro yang terkait dengan kepatuhan pajak ataupun pencairan belanja untuk pelaksanaan APBN. Situasi yang terkini dari implementasi teknologi informasi di lingkungan pengelolaan keuangan negara mengarah pada analitika data sebagai upaya dari berbagai otoritas pengelolaan keuangan negara untuk mendapatkan insights dari data yang berada dalam cakupan kewenangannya untuk digunakan sebagai pendukung pengambilan keputusan atau kebijakan keuangan negara [7], [8].

Perkembangan analitika data pada pemerintahan telah menunjukkan perkembangan yang pesat. Archeena dan Anita [9] menekankan bahwa tantangan analitika data publik di pemerintahan bukan karena kurangnya data, namun kurangnya informasi yang mendukung pengambilan keputusan, perencanaan dan strategi. Limpahan data (data deluge) umumnya diolah untuk kepentingan dukungan kota pintar (smart cities) sebagaimana ditekankan Watson [10]. Analitika data publik untuk pemerintahan terus dikembangkan manfaatnya dengan bentuk data terhubung (linked data) dan inisiatif Open Government Data (OGD) [11], [12].

Analitika data pada dasarnya dapat digunakan untuk mendukung semua fungsi keuangan negara [5], [6], [13], [14]. Namun karena data yang berhubungan dengan pengelolaan keuangan negara sangatlah beragam, kajian ini memilih untuk menggunakan data dasar Dana Alokasi Umum (DAU) yang telah disediakan secara terbuka (open data) sebagai use case (lihat misalnya [15], [16]) dalam kajian ini. Data dasar DAU tersebut dapat diakses melalui tautan dalam situs web Direktorat Jenderal Perimbangan Keuangan (DJPK) sebagai bagian dari Kementerian Keuangan sebagai pengelola keuangan negara yang bertugas untuk mengelola dana transfer dari pemerintah pusat ke pemerintah daerah. Penggunaan data yang telah tersedia untuk publik ini pada gilirannya diharapkan dapat mendorong para pemangku kepentingan pengelolaan keuangan negara untuk menggunakan pengetahuan yang didapatkan dari hasil kajian sebagai salah satu referensi dalam melakukan pengolahan dan analisis data keuangan negara dengan area implementasi yang lebih luas.
Penelitian ini dengan menggunakan metode observational case studies [17] sebagai salah satu metode dalam lingkup design science methodology [18]-[22] bertujuan untuk menghasilkan suatu artefak teknologi informasi berupa prosedur penggunaan perangkat lunak yang dengan menerapkan kerangka pengetahuan analitika data (data analytics as body of knowledge) untuk kepentingan pengelolaan keuangan negara [23] dengan menggunakan use case data dasar DAU. Manfaat yang diharapkan dapat diperoleh dari hasil penelitian ini adalah adanya tambahan rujukan yang dapat digunakan oleh para pemangku kepentingan keuangan negara dalam menjalankan masingmasing perannya.

Direktorat Jenderal Anggaran [24] merumuskan keuangan negara dengan menggunakan beberapa sudut pandang yaitu: subjek, dan objek, proses dan tujuan. Dari sudut pandang subjeknya, keuangan negara meliputi keseluruhan pelaku yang terkait dengan pengelolaan objek berupa semua hak dan kewajiban negara yang dapat dinilai dengan uang, termasuk kebijakan dan kegiatan dalam bidang fiskal, moneter dan pengelolaan kekayaan negara yang dipisahkan, serta segala sesuatu baik berupa uang, maupun berupa barang yang dapat dijadikan milik negara berhubung dengan pelaksanaan hak dan kewajiban tersebut. Sementara dari sudut pandang proses, keuangan negara adalah seluruh rangkaian kegiatan yang berkaitan dengan pengelolaan objek sebagaimana tersebut dari perumusan kebijakan, pengambilan keputusan hingga pertanggunggjawaban. Sedangkan dari sisi tujuan, merupakan seluruh kebijakan, kegiatan dan hubungan hukum yang berkaitan dengan pemilikan dan/atau penguasaan objek dalam rangka penyelenggaraan pemerintahan negara. Pelaksanaan pengelolaan keuangan negara dari semua sudut pandang di atas memerlukan data sebagai proses pendukung pengambilan keputusan:

“... dalam pembahasan dan analisis program-program pembangunan nasional dan anggaran, data mengenai perkembangan alokasi dan realisasi anggaran dalam APBN terkait dengan kegiatan pada bidang-bidang tertentu, juga dibutuhkan dalam pengambilan keputusan. Anggaran bidang tertentu (tematik) tersebut perlu disiapkan sebagai upaya untuk mendukung penerapan performance-based budgeting, dalam arti penganggaran yang telah dan akan dilakukan disertai dengan capaian dan target yang akan dihasilkan di bidang-bidang tertentu. ..." [24].

Kajian [5] menunjukkan perlunya pengembangan analitika data sebagian dari keseluruhan sistem informasi manajemen keuangan negara di Indonesia. Terkait dengan implementasi analitika data sebagai dengan sistem informasi manajemen keuangan ini diuraikan bahwa:

“... Melanjutkan pengembangan DW dan data analytics serta penyatuan berbagai monitoring system dalam satu aplikasi terintegrasi (OLAP). ... Data analytics, termasuk penggunaan BI dapat dilakukan sebagai basis untuk simulasi kebijakan, sistem monitoring terintegrasi untuk semua $\mathrm{K} / \mathrm{L}$ dan satker, pertukaran data dengan stakeholders terkait, pengembangan berbagai mobile applications untuk menyampaikan hasil-hasil pembangunan ataupun 
pengikutsertaan masyarakat dalam monitoring pembangunan."

Demikian pula kajian [13] yang menyatakan perlunya setiap bidang pengelolaan keuangan negara agar menjadikan analitika data sebagai bagian dari inisiatif strategis bidang tersebut terutama yang terkait dengan implementasi sistem informasi dan manajemen data.

Penelti [25] mendefinisikan analitika data dengan proses dan metode dalam analisis data sehingga akhirnya dari data tersebut didapatkan wawasan yang mendalam (meaningful insight) tentang suatu tema. Sementara itu [26] menyatakan bahwa analitika adalah penggunaan data, analisis kuantiatif, model eksplanatori dan prediktif, serta manajemen berbasisfakta secara ekstentif untuk mempercepat keputusan dan tindakan. Analitika bukanlah suatu hal yang sama sekali baru. Istilah ini sebenarnya merupakan perkembangan dari berbagai istilah yang ada sebelumnya. Pada tahun 1970an, istilah yang banyak digunakan adalah Decision Support Systems (DSS). Kemudian pada era 1980an nama yang digunakan untuk hal ini adalah Online Analytical Processing (OLAP) dan Executive Information Systems (EIS). Setelah itu, tahun 1990an muncul istilah baru yang populer yaitu Business Intelligence (BI). Pada tahap berikutnya, istilah analytics dan juga data science mulai digunakan secara luas.

Berdasarkan uraian di atas dapat disimpulkan bahwa analitika data adalah sebuah kerangka pengetahuan sebagai panduan untuk mengolah berbagai jenis/format data dengan bermacam-macam teknik pengolahan dan analisis data sehingga memungkinkan penyajian informasi yang dapat digunakan untuk mendukung pengambilan keputusan. Dalam hal ini, terdapat perbedaan antara analitika (analytics) dengan analisis (analysis). Analisis adalah tindakannya, sementara analitika adalah kerangka pengetahuan (body of knowledge) yang digunakan untuk melakukan analisis [25], [27].

Berbagai kerangka konseptual analitika data membedakan hal ini berdasarkan kompleksitas proses pengolahan informasinya. Merujuk [28] menyatakan bahwa data analytics berdasarkan kompleksitas prosesnya dapat dibagi menjadi empat, yaitu: (1) descriptive: summarizes activity or masters data based on certain attributes; (2) diagnostic: detects correlations and patterns of interest; (3) predictive: identifies common attributes or patterns that may be used to identify similar activity; dan (4) prescriptive: recommends action based on previously observed actions. Sementara itu [25] dan juga [26] membedakan menjadi tiga saja yaitu: deskriptif, prediktif dan preskriptif. Penjelasan ketiga hal tersebut sebagaimana terlihat dalam Gambar 1.

Dalam kaitannya dengan implementasi analitika data untuk pengelolaan keuangan negara, penulis mengadaptasi penjelasan [25] dan menggunakannya untuk menjelaskan analitika data sebagaimana terpampang dalam Tabel 1.

Tulisan ini, dengan merujuk kajian Febrian dan Darono (2019), mengajukan definisi operasional analitika data keuangan negara sebagai sekumpulan kerangka konseptual yang digunakan untuk mengidentifikasi, mengekstraksi, dan mendapatkan pola atau anomali tertentu dari berbagai data keuangan negara untuk selanjutnya dapat disajikan dalam bentuk wawasan (insights), visualisasi ataupun model yang diharapkan dapat membantu pengambilan keputusan yang berkaitan dengan pengelolaan keuangan negara secara keseluruhan.

$\left.\begin{array}{|l|l}\text { Optimization } & \text { "What's the best that can happen?" } \\ \hline \text { Randomized Testing } & \text { "What if we try this?" }\end{array}\right\}$ Prescriptive Analytics

Gambar 1. Tiga Tingkatan Dalam Analitika Data Davenport (2013)

Tabel 1. Perbandingan Hal Yang Dilakukan Dalam Tingkatan Analitika Data

\begin{tabular}{|c|c|c|}
\hline $\begin{array}{c}\text { Jenis } \\
\text { Analitika }\end{array}$ & $\begin{array}{l}\text { Hal Yang } \\
\text { Dilakukan }\end{array}$ & Contoh \\
\hline Deskriptif & $\begin{array}{l}\text { Apa yang } \\
\text { sedang atau } \\
\text { telah terjadi }\end{array}$ & $\begin{array}{l}\text { Berapa besarnya } \\
\text { perbandingan antara } \\
\text { penerimaan Pajak } \\
\text { Penghasilan (PPh) dengan } \\
\text { Pajak Pertambahan Nilai } \\
\text { (PPN) dalam sepuluh tahun } \\
\text { terakhir? }\end{array}$ \\
\hline Prediktif & $\begin{array}{l}\text { Apa yang } \\
\text { mungkin } \\
\text { terjadi }\end{array}$ & $\begin{array}{l}\text { Berapa kira-kira besarnya } \\
\text { antara perbandingan PPh } \\
\text { dengan PPN untuk jangka } \\
\text { waktu tiga tahun yang akan } \\
\text { datang? }\end{array}$ \\
\hline Preskriptif & $\begin{array}{l}\text { Apa yang } \\
\text { yang } \\
\text { seharusnya } \\
\text { kita lakukan }\end{array}$ & $\begin{array}{l}\text { Seharusnya penerimaan } \mathrm{PPh} \\
\text { lebih besar dari penerimaan } \\
\text { PPN, bagaimana agar } \\
\text { keadaan itu bisa terwujud? }\end{array}$ \\
\hline
\end{tabular}

Sumber: hasil analisis penulis, diadaptasi dari Lee (2017)

Definisi operasional tersebut kemudian digunakan untuk mengembangkan artefak teknologi informasi berupa prosedur penggunaan perangkat lunak untuk mengolah dan menganalisis data, dengan use case data dasar DAU. Use case adalah deskripsi operasional naratif yang bisa juga disertai dengan diagram tentang bagaimana suatu sistem digunakan. Diagram ini menggambarkan batasan dari sebuah sistem (aplikasi), aktor yang terlibat, aktivitas untuk menyelesaikan tugas tertentu dan hubungan antar aktor dengan aktivitasnya [29], [30]. Merujuk berbagai uraian di atas, use case untuk analisis data dasar DAU yang digunakan penelitian ini dipaparkan dalam Gambar 2. 


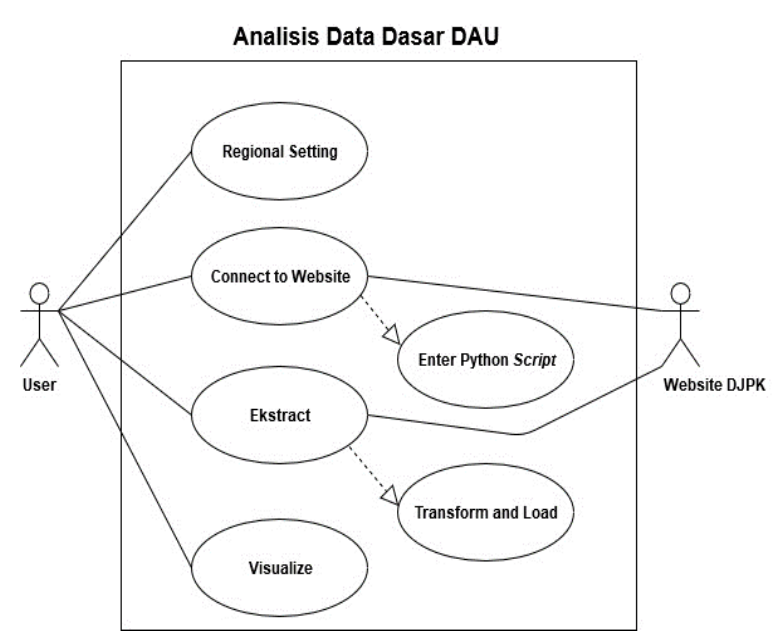

Gambar 2. Use Case Untuk Analisis Data Dasar DAU

Secara umum sistem yang akan dibuat dapat digambarkan dengan Diagram Blok pada Gambar 3. Alur kerja yang digambarkan dalam Blok Diagram Sistem adalah user melakukan komunikasi dengan sistem website DJPK dengan menggunakan aplikasi Power BI Desktop di komputer. Power BI Desktop memberikan input untuk mengatur regional setting sesuai dengan pembacaan data angka dan tanggal di website. Setelah itu, Power BI Desktop mengektraksi data website menggunakan python script agar didapatkan tabel data secara berulang yang kemudian ditransformasi sesuai dengan kebutuhan dan di-load untuk disimpan di penyimpanan lokal. Setelah itu dilakukan output data berupa visualisasi analisis 10 besar DAU/luas wilayah, analisis penduduk/luas wilayah, analisis IKK per provinsi dan analisis DAU/luas wilayah dengan peta.

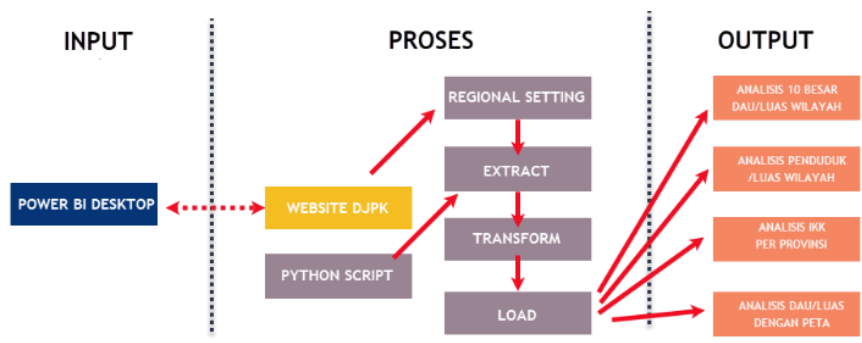

Gambar 3. Diagram Blok Analisis

Selanjutnya, bagian kedua akan menyajikan rancangan penelitian yang menjelaskan bagaimana design science methodology dapat diterapkan untuk penelitian ini. Berikutnya, bagian ketiga akan berisi tentang diskusi penelitian untuk menjawab pertanyaan penelitian. Terakhir, bagian keempat menyajikan kesimpulan dan rekomendasi penelitian.

\section{METODE PENELITIAN}

Peneliti [20] menyatakan bahwa penelitian yang berkaitan dengan pengelolaan keuangan dapat menggunakan memanfaatkan kerangka kerja ditetapkan dalam design science methodology. Selanjutnya [19] mendefinisikan sains desain (design science) sebagai kajian ilmiah dan kreasi atas berbagai artefak untuk dapat digunakan oleh manusia sebagai sarana dalam menyelesaikan masalah praktis tertentu yang menjadi bagian dari keseluruhan masalah yang ingin diselesaikan.

Berikut ini adalah penjelasan ringkas tentang design science methodology dengan merujuk gagasan dan kajian yang dilakukan oleh [17] dan juga [19]. Metodologi ini merupakan penelitian untuk merancang atau menelaah artefak sesuai dengan konteksnya. Artefak dalam hal ini adalah metode, teknik, notasi, dan algoritma yang digunakan dalam sebuah sistem informasi. Sementara itu konteks adalah bagaimana artefak tersebut dirancang, digunakan, dievaluasi, diperbaiki, atau dihapus dari suatu sistem informasi. Artefak sesuai dengan konteksnya ditujukan untuk memecahkan masalah dalam suatu bidang/praktik tertentu.

Design research dipilih sebagai rancangan penelitian ini dengan strategi penelitian pengembangan model dan instantiasi berupa artefak yang berkaitan dengan analitika data dasar dana alokasi umum (lihat misalnya: [31], [32]). Pengumpulan dan analisis data menggunakan studi dokumentasi dengan analisis data kualitatif berupa kesesuaian antara teknologi yang tersedia dengan permasalahan yang akan diselesaikan. Berdasarkan [33], [34] diartikan sebagai: (1) konstruksi (constructs): vocabulary and symbols, bahasa atau ungkapan untuk memformulasikan fenomena; (2) model (abstractions and representations, abstraksi atau penyederhanaan dari entitas di dunia nyata untuk mengurangi kompleksitas; (3) metode (methods): algorithms and practices, panduan untuk penentuan solusi atas suatu masalah, langkah demi langkah yang merujuk kepada model yang telah dibuat; (4) instantiasi (instantiations): implemented and prototype systems, implementasi dari konstruksi, model atau metode untuk penyelesaian masalah nyata yang sedang dihadapi.

Berdasarkan uraian di atas maka penelitian ini menggunakan design science methodology karena sesuai tujuannya untuk mengembangkan sebuah artefak berupa prosedur penggunaan berbagai perangkat lunak yang dapat mendukung implementasi analitika data keuangan negara dengan use case data dasar DAU. Langkah penelitian yang yang dilakukan dalam penelitian ini untuk melaksanakan metode observational case studies [17] adalah:

(1) Menetapkan perangkat yang digunakan, dalam hal ini adalah Python untuk ekstraksi dan Power BI Desktop untuk transformasi data, analisis dan visualisasi data;

(2) Mengevaluasi kode dalam bahasa Python yang dikembangkan oleh [35] yang agar bisa digunakan (deployed) untuk kepentingan artefak berupa pembuatan template file dalam format PBIX yang dapat digunakan untuk mengolah data dasar DAU;

(3) Memasukkan kode bahasa Python menjadi objek dalam Power BI Desktop;

(4) Melakukan urutan perintah pengolahan data dalam Power BI Desktop sehingga data dasar DAU dapat diolah, dianalisis dan divisualisasikan. 
Analitika data yang digunakan dalam kajian ini adalah analisis deskriptif dengan didukung oleh beberapa teknik visualisasi data.

\section{HASIL DAN PEMBAHASAN}

Bagian pembahasan ini akan terdiri dari empat subbagian. Keempat bagian ini disajikan sebagai pembahasan yang berurutan. Pada bagian ini akan menjelaskan langkahlangkah yang dilakukan untuk melakukan analitika data DAU menggunakan Power BI Desktop. Prosedur yang dilaksanakan sesuai dengan use case yang sudah dikembangkan adalah sebagai berikut:

(1) Mengidentifikasi struktur data website yang menjadi sumber data dasar DAU;

(2) Mempersiapkan data peta yang tersedia di internet yang sesuai dengan kebutuhan analisis data dasar DAU;

(3) Mempersiapkan script Python dan Power BI Desktop;

(4) Extract, transform dan load menggunakan Power BI Desktop;

(5) Analitika data DAU menggunakan visualisasi pada Power BI Desktop.

\section{a. Mengidentifikasi Struktur Website Yang Menyediakan Data Sumber}

Berikut adalah tampilan struktur website data sumber yang dapat dilihat pada Gambar 4.

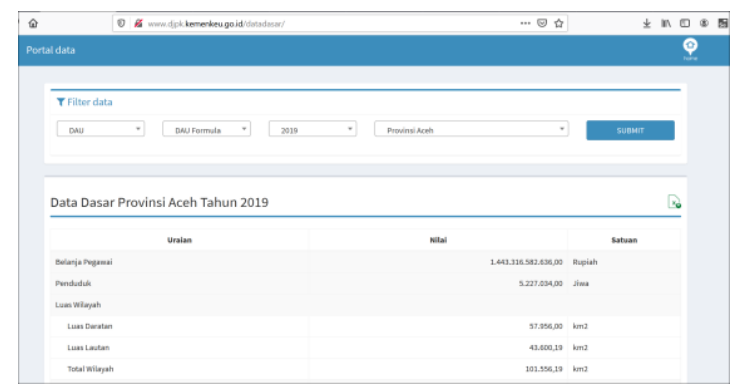

Gambar 4. Website www.djpk.kemenkeu.go.id/datadasar

Selanjutnya, jumlah data yang akan diekstraksi dengan filter data jenis dana DAU, subjenis DAU Formula dan Tahun 2018 untuk seluruh provinsi, kota dan/atau kabupaten yang ada di Indonesia adalah sebanyak 542. Berikut adalah skenario langkah yang digunakan untuk mengekstraksi 542 data yang dapat dilihat pada Gambar 5.

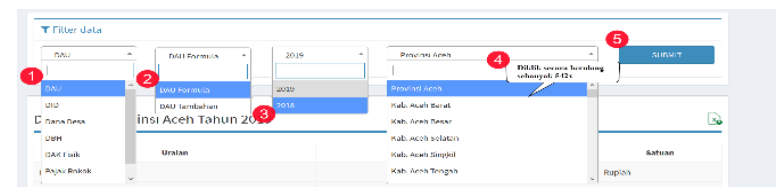

Gambar 5. Skenario web scrape Data Dasar DAU

\section{b. Mempersiapkan Data Peta}

Untuk kepentingan visualisasi sebagai bagian dari analitika data, salah satu data yang perlu dipersiapkan pertama kali adalah data peta. Visualisasi yang akan disajikan dalam tulisan ini adalah data DAU per provinsi/kabupaten/kota dengan menggunakan tampilan grafis berupa peta Indonesia.

Salah satu visualisasi yang tersedia di Power BI Desktop adalah ArcGIS Maps. ArcGIS Maps adalah sebuah mapping platform/sistem pemetaan online yang dibuat oleh perusahaan ESRI. Peta ini dipilih karena memiliki kemampuan untuk untuk pengumpulan, penyimpanan, pengambilan, analisis dan penyajian data spasial jenis apa pun [36], [37]. Data spasial yang digunakan adalah data lokasi dari Kota atau Kabupaten yang ditambahkan kata "Indonesia" pada bagian akhir. Dari data lokasi yang telah dibuat maka dapat ditampilkan oleh ArcGis Maps, Peta lokasi Indonesia yang dapat dilihat secara lebih rinci pada bagian berikutnya.

\section{c. Mempersiapkan Script Python Dan Power BI Desktop}

Untuk membantu mengekstrak data DAU Formula tahun 2018 sebanyak 542 kali, maka penulis menggunakan kode Python yang tersedia pada link website http://bit.ly/BetaAutomasiDataDasarDAU [35]. Sesuai syarat dan ketentuan dalam tautan tersebut, kode ini dapat diubah dan digunakan kembali secara bebas. Untuk itu, kode terlebih dulu diedit agar data keluarannya sesuai dengan yang dibutuhkan dan dalam format yang dikenali oleh perangkat Power BI Desktop.

Sebelum mengekstraksi website menggunakan kode Python tersebut, pada Power BI Desktop dilakukan pengaturan awal terkait dengan Regional Setting dari website data dasar DAU yaitu Indonesia. Langkahnya adalah sebagai berikut:

a. Buka Power BI Desktop $\rightarrow$ File $\rightarrow$ Options and settings $\rightarrow$ Options,

b. Regional Settings $\rightarrow$ select Indonesia.

Tujuan dari pengaturan Regional Setting adalah menghasilkan pembacaan data yang benar oleh Power BI Dekstop untuk jenis data berupa angka dari website yang akan diekstraksi.

\section{d. Extract, Transform, dan Load Menggunakan Power BI Desktop}

Langkah berikutnya adalah melakukan Extract, Transform dan Load (ETL) data DAU Formula tahun 2018. Langkah yang dilakukan adalah sebagai berikut:

1) Buka menu Power BI Desktop $\rightarrow$ Get Data $\rightarrow$ More $\rightarrow$ Other $\rightarrow$ Python script $\rightarrow$ Connect (lihat Gambar 6).

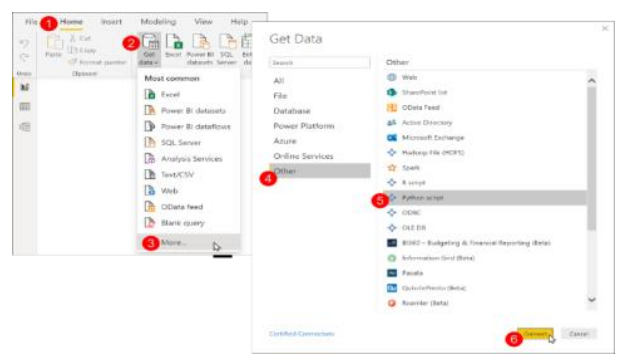

Gambar 6. Get Data dari Power BI dengan Python Script

2) Pada kolom Python script, pindahkan kode yang telah dipersiapkan (lihat Gambar 7). 


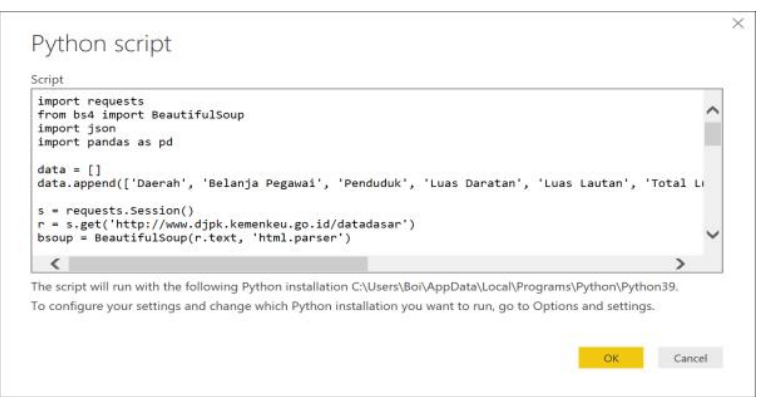

Gambar 7. Insert Python Script ke Power BI

3) Pada jendela Power BI, pilih menu Navigator $\rightarrow$ Transform.

4) Selanjutnya baris pertama yang telah berisi data dijadikan sebagai header dengan cara klik menu Home $\rightarrow$ Use First Row as Headers.

5) Tambahkan satu kolom untuk mengidentifikasi pada setiap detail apakah Provinsi atau Kab/Kota dengan cara klik Add Column $\rightarrow$ Conditional Column lalu isi variabel seperti pada gambar di bawah ini $\rightarrow O k \rightarrow$ Validasi tipe data menjadi Text sebagaimana dapat dilihat pada Gambar 8 .

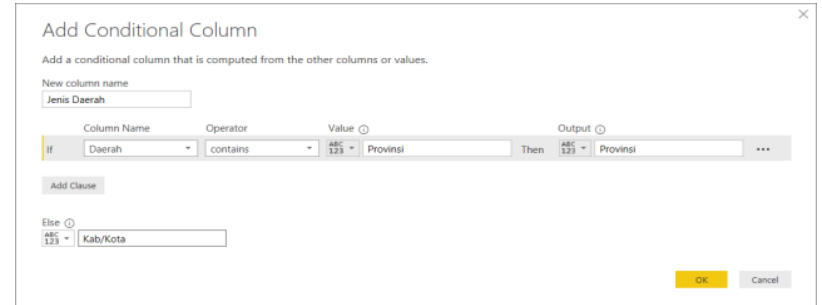

Gambar 8. Add Conditional Column Pada Power BI

6) Tambahkan kolom satu lagi yang akan digunakan sebagai identitas lokasi untuk membuat visualisasi peta dengan cara klik Add Column $\rightarrow$ Custom Column lalu isi variabel seperti pada gambar di bawah ini $\rightarrow$ klik $O k \rightarrow$ Validasi tipe data menjadi Text sebagaimana dapat dilihat pada Gambar 9.

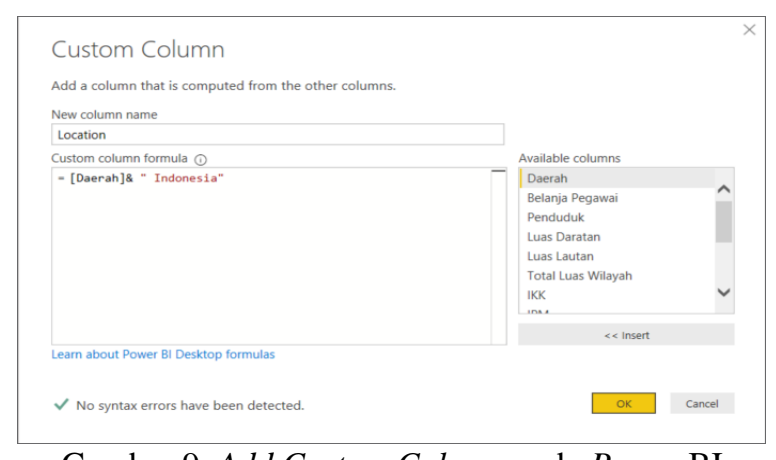

Gambar 9. Add Custom Column pada Power BI

7) Setelah selesai melakukan transformasi, selanjutnya data DAU 2018 sudah dapat dimuat dengan cara klik menu Home $\rightarrow$ Close \& Apply.
8) Sebelum melakukan visualisasi pada Data Model, berikan gaya koma (style comma) pada kolom Belanja Pegawai, Penduduk, Luas Daratan, Luas Lautan, Total Luas Wilayah, IKK, IPM, PDRB per kapita, PAD, DBH Pajak, DBH SDA dan Alokasi DAU. Selain itu ubah kategori data kolom Location dari Text menjadi City.

\section{e. Analitika Data DAU Menggunakan Visualisasi Pada Power BI Desktop}

Selanjutnya, analitika data DAU telah dapat dilakukan dengan memvisualisasi menggunakan Power BI Desktop.

(1) Analisis 10 Besar Data DAU dibandingkan dengan Total Luas Wilayah.

Untuk membantu mengekstrak data DAU Formula tahun 2018 sebanyak 542 kali, maka penulis menggunakan kode Python yang tersedia pada Analisis 10 Besar Data DAU dibandingkan dengan Total Luas Wilayah.

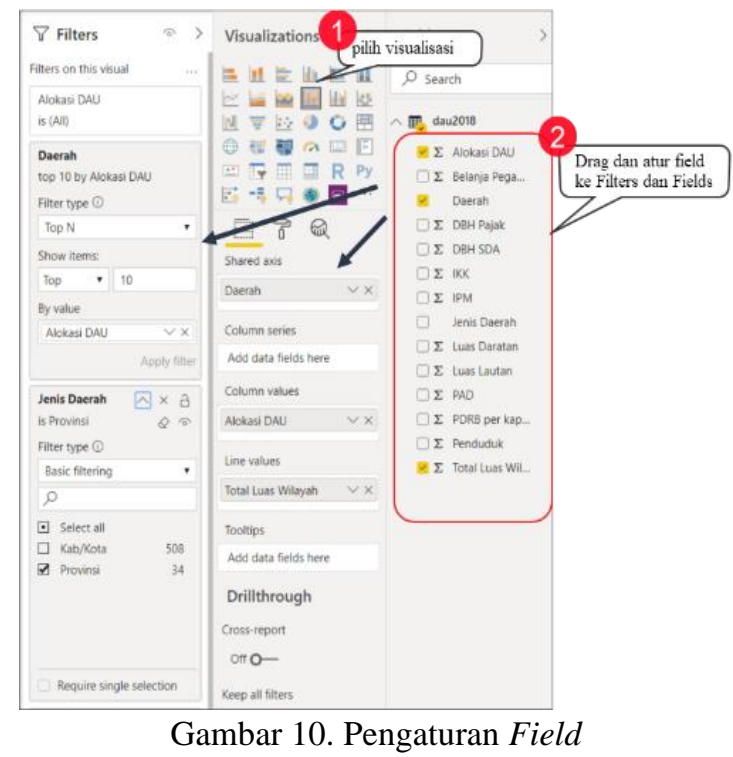

Hasil visualisasi untuk 10 Besar Data DAU dibandingkan dengan Total Luas Wilayah untuk Provinsi dapat dilihat pada Gambar 11.

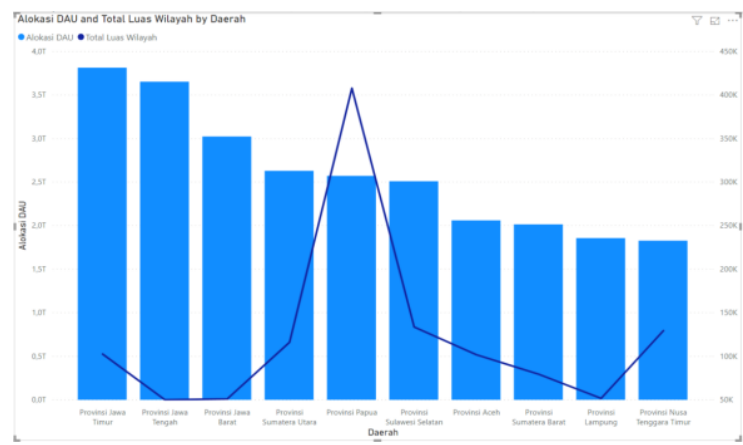

Gambar 11. Visualisasi Top 10 DAU Dibandingkan Dengan Total Luas Wilayah

Dari visualisasi tersebut dapat diketahui 10 besar DAU untuk provinsi dan terdapat penyimpangan pada Provinsi 
Papua dimana dengan total luas wilayah tertinggi akan tetapi alokasi DAU-nya hanya berapa di posisi ke-5.

(2) Analisis Penduduk dibandingkan dengan Total Luas Wilayah untuk Kabupaten/Kota.

Untuk menganalisis Penduduk dibandingkan dengan Total Luas Wilayah untuk Kabupaten/Kota, langkahnya pilih Visualisasi Scatter Chart $\rightarrow$ Tarik dan atur field ke Filters dan Fields sebagaimana dapat dilihat pada Gambar 12.

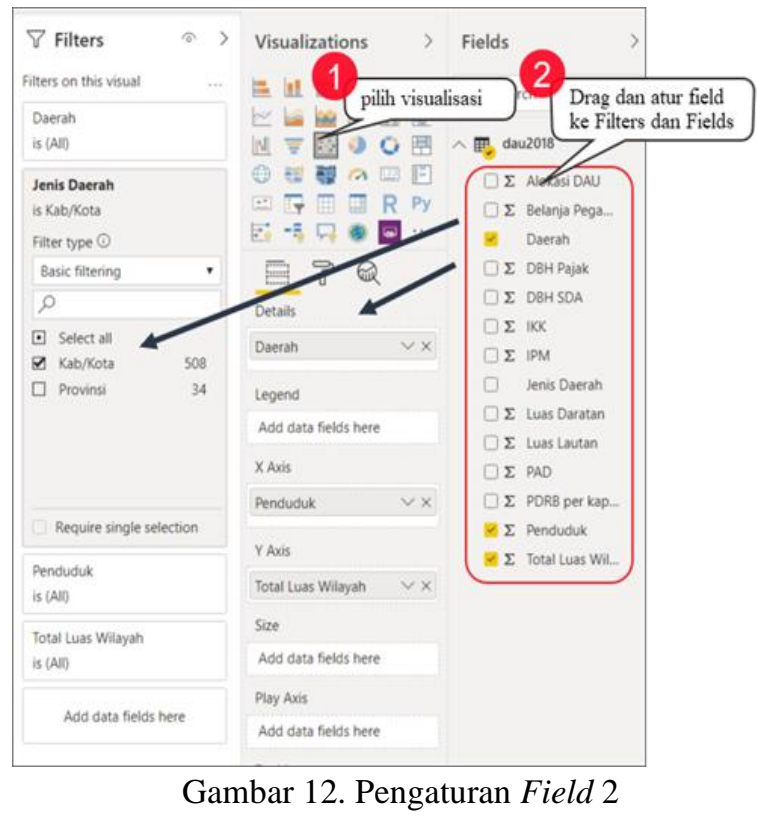

Hasil visualisasi untuk Analisis Penduduk dibandingkan dengan Total Luas Wilayah untuk Kabupaten/Kota dapat dilihat pada Gambar 13.

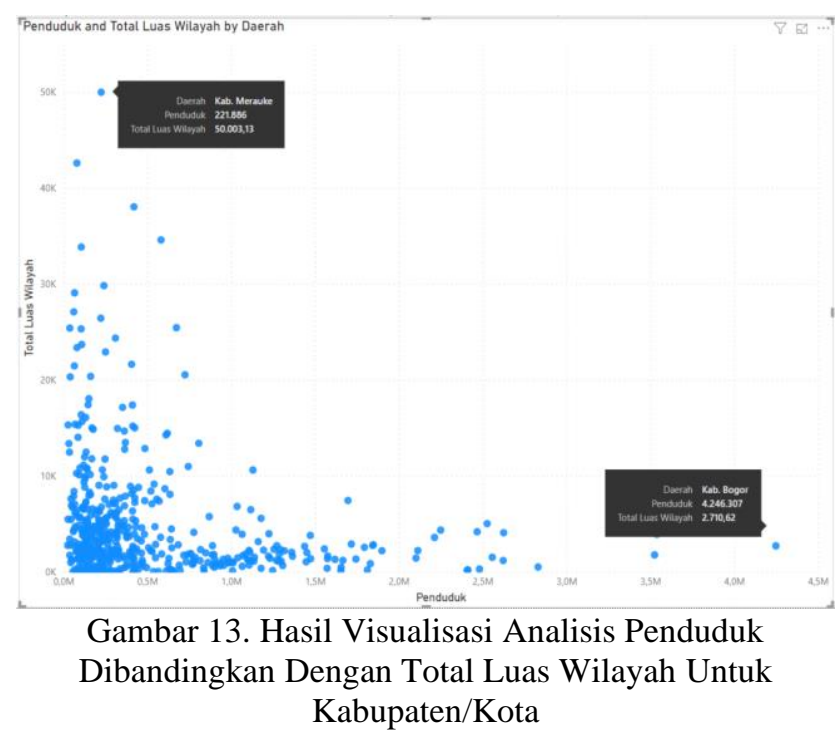

Dari hasil visualisasi, dapat dianalisis terdapat 2 kabupaten yang menyimpang jauh dari yang lainnya yaitu Kab. Bogor (penduduk terbanyak) dan Kab. Merauke (terluas wilayah).
(3) Analisis IKK per Provinsi.

Untuk menganalisis IKK per Provinsi, langkahnya pilih Visualisasi Scatter Chart $\rightarrow$ Tarik dan atur field ke Filters dan Fields sebagaimana dapat dilihat pada Gambar 14.

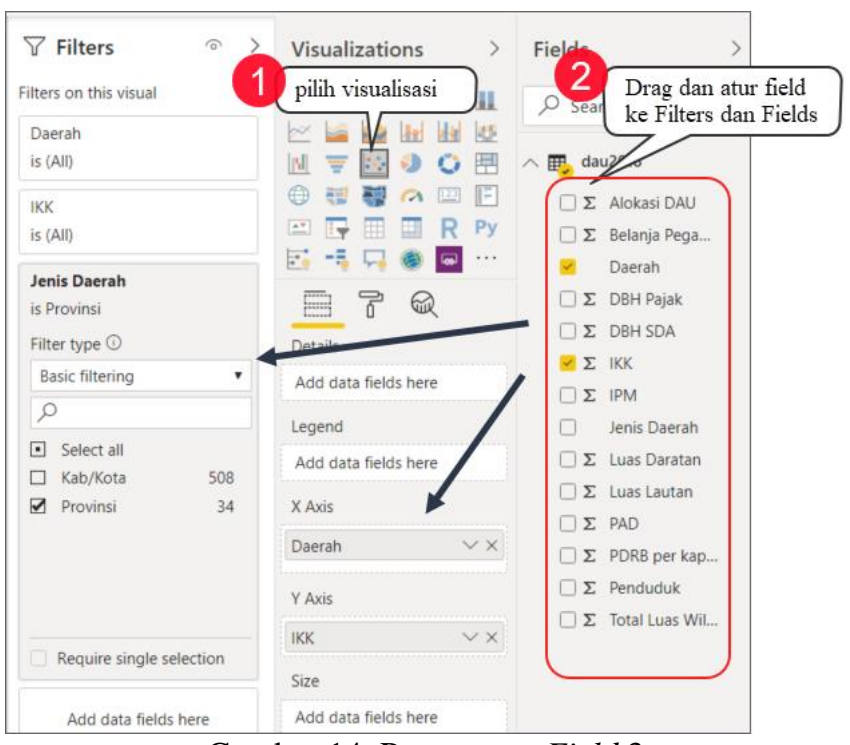

Gambar 14. Pengaturan Field 3

Hasil visualisasi untuk IKK per Provinsi dapat dilihat pada Gambar 15.

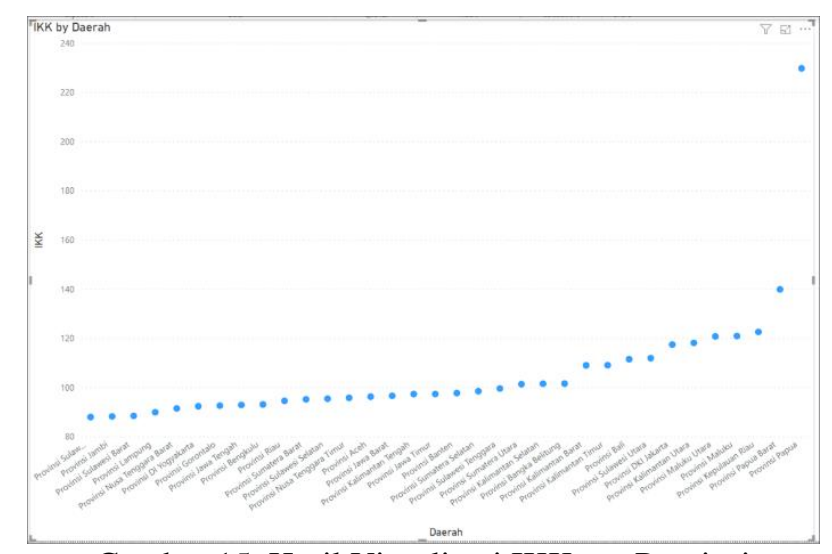

Gambar 15. Hasil Visualisasi IKK per Provinsi

Dari hasil visualisasi, dapat Provinsi Papua memiliki IKK yang paling tinggi (tidak sejahtera) dan Provinsi Sulawesi Tengah memiliki IKK yang paling rendah (sejahtera).

(4) Analisis data DAU dibandingkan dengan Total Luas Wilayah menggunakan Peta.

Untuk menganalisis data DAU dibandingkan dengan Total Luas Wilayah menggunakan Peta, langkahnya pilih Visualisasi ArcGIS Map sebagaimana dijelaskan pada bagian sebelumnya $\rightarrow$ Drag dan atur field ke Filters dan Fields sebagaimana dapat dilihat pada Gambar 16. 


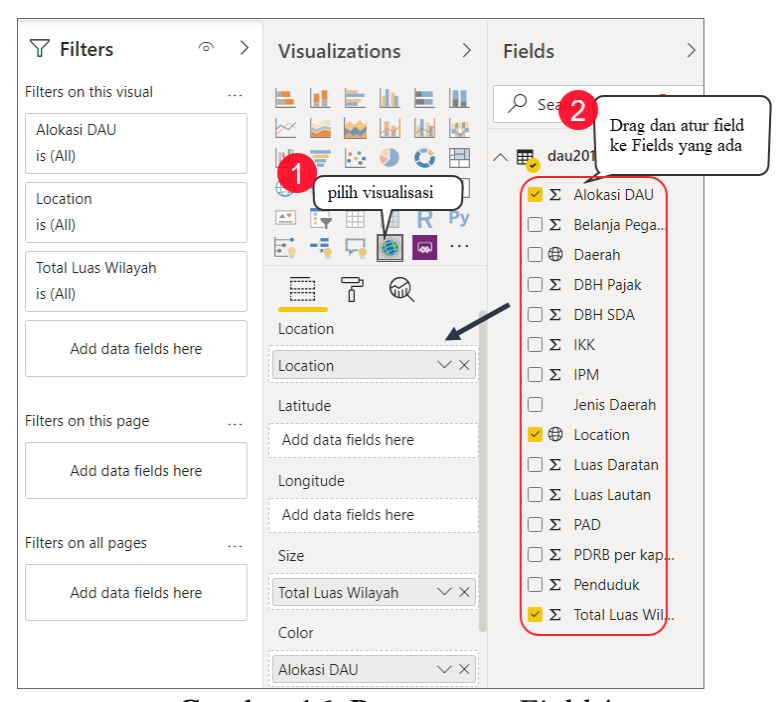

Gambar 16. Pengaturan Field 4

Selanjutnya kita buat visualisasi satu lagi sebagai menu filter panel yang memuat Jenis Daerah dengan cara klik pada area kosong pada canvas $\rightarrow$ Visualisasi Table $\rightarrow$ Tarik fields Jenis Daerah ke Values sebagaimana dapat dilihat pada Gambar 17.

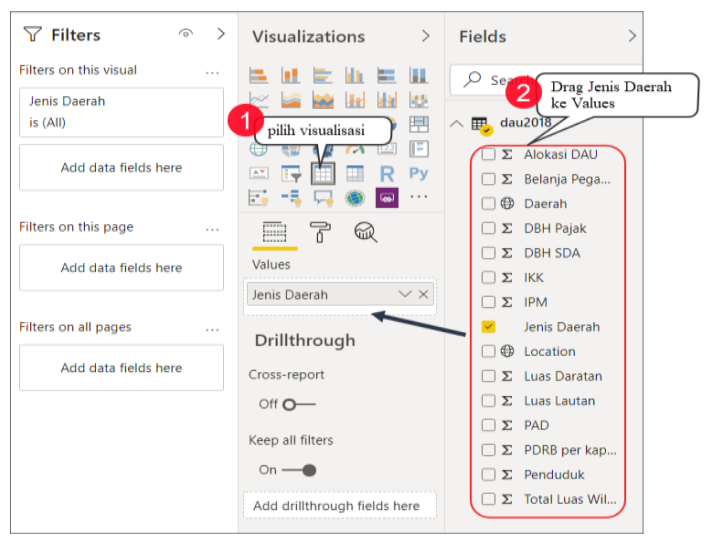

Gambar 17. Pengaturan Field 5

Hasil visualisasi untuk Analisis data DAU dibandingkan dengan Total Luas Wilayah menggunakan Peta dapat dilihat pada Gambar 18.

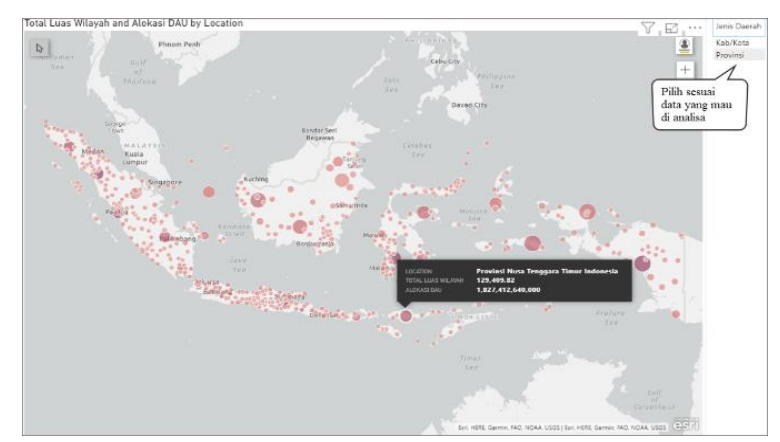

Gambar 18. Hasil Visualisasi Map

Dari hasil visualisasi, dapat dilihat apabila lingkaran semakin besar lingkaran, maka mencerminkan Total Luas
Wilayah yang semakin besar. Sedangkan apabila warna dari lingkaran semakin tua, maka Alokasi DAU semakin besar.

\section{KESIMPULAN DAN SARAN}

Analitika data merupakan bagian yang tidak terpisahkan dari pengelolaan keuangan negara. Penelitian ini berupaya untuk menghasilkan suatu artefak aplikasi teknologi informasi berupa prosedur penggunaan perangkat Power BI Desktop untuk menyajikan analisis data dasar DAU dengan pendekatan visualisasi - deskriptif. Penelitian menyimpulkan bahwa implementasi analitika data keuangan negara bergantung pada dua hal utama: (1) penyediaan data keuangan negara secara bebas di situs web pengelola keuangan negara (dalam hal ini data dasar DAU) dengan struktur yang mudah diolah kembali memungkinkan para pihak yang berkepentingan dengan data tersebut mempunyai kesempatan untuk memanfaatkan data sesuai dengan kepentingannya, hal ini bahkan bisa jadi dilakukan oleh sesama instansi di bawah Kementerian Keuangan karena belum tentu data yang diinginkan oleh satu unit dapat diakses dengan mudah oleh unit yang lain; (2) analitika data keuangan negara dapat dilakukan dengan menggunakan perangkat yang tersedia secara bebas (tanpa biaya akuisisi), dalam hal use case ini yang digunakan adalah Python dan Power BI Desktop, artinya analitika data keuangan negara bisa dilakukan oleh siapa saja yang menginginkannya.

Tulisan berkontribusi kepada praktik analitika keuangan negara setidaknya dari dua hal: (1) mengajukan definisi operasional analitika data keuangan negara; (2) mengembangkan use case dari data yang tersedia secara bebas dengan menggunakan perangkat lunak yang juga tersedia secara bebas. Penggunaan perangkat berupa Python dan Power BI Desktop dalam penelitian ini perlu dilihat sebagai pilihan praktis saja. Pilihan atas perangkat yang lain tentu saja sangat terbuka, bergantung pada kemampuan dan kebutuhan data analyts yang akan menggunakan data keuangan negara.

Saran penulis adalah pembentukan satu portal data di situs web Kementerian Keuangan yang menginformasikan data keuangan negara apa yang telah tersedia terkait dengan fungsi pengelolaan keuangan negara yang berada di bawah kewenangannya. Pada situasi yang paling minimal, portal ini dapat berupa hanya direktori data saja sehingga pengguna dengan menggunakan berbagai teknik dan perangkat analitika data yang dimilikinya ada memanfaatkan data tersebut sesuai dengan kepentingannya.

\section{REFERENSI}

[1] Gover, J. (2018). How to Do Data Analytics in Government. Diakses dari: https://www.govtech.com/ data/how-to-do-data-analytics-in-government.html

[2] Johnson, N.B. (2016). How You Can Use Data Analytics to Change Government. https://www.govloop.com/wp-content/uploads/2016/ 01/DataAnalyticsGuide.pdf 
[3] Kreuter, F., Ghani, R. \& Lane, J. (2019). Change Through Data: a Data Analytics Training Program for Government Employees. Harvard Data Science Review, Vol. 1(2), pp. 1-26.

[4] Misch, F., Olden, M.B., Poplawski-Ribeiro, M., \& Kejji, L. (2017). Nowcashing: Using Daily Fiscal Data for Real-Time Macroeconomic Analysis. International Monetary Fund.

[5] Sudarto, S. (2019). Pengembangan integrated financial management information system (IFMIS) di Indonesia. Indonesian Treasury Review: Jurnal Perbendaharaan, Keuangan Negara Dan Kebijakan Publik, Vol. 4(2), pp. 87-103.

[6] Tableu. (n.d.). Finance Analytics for Government. Diakses dari https://www.tableau.com/solutions/ government-finance-analytics

[7] Lineberry, D. (2017). Government Data Analytics Center (GDAC) Annual Report. Department of Information Technology GDAC.

[8] Viechnicki, P., \& Trujillo, J.L. (n.d.). 3 Trends Powering Rapid Growth in Government Analytics. https://www2.deloitte.com/us/en/pages/public-sector/ articles/government-analytics-trends.html

[9] Archenaa, J. \& Anita, E. M. (2015). A Survey of Big Data Analytics in Healthcare and Government. Procedia Computer Science, Vol. 50, pp. 408-413.

[10] Watson, R.B. \& Ryan, P.J. (2020). Big Data Analytics in Australian Local Government. Smart Cities, Vol. 3(3), pp. 657-675.

[11] Kalampokis, E., Tambouris, E. \& Tarabanis, K. (2013). Linked Open Government Data Analytics. Electronic Government (EGOV 2013), pp. 99-110.

[12] Alzamil, Z.S. \& Vasarhelyi, M.A. (2019). A New Model for Effective and Efficient Open Government Data. International Journal of Disclosure and Governance, Vol. 16(4), pp. 174-187.

[13] Darono, A. \& Febrian, F. (2020). Government Financial Data Analytics: An Indonesian Perspective. In Public Sector Accountants and Quantum Leap: How Far We Can Survive in Industrial Revolution 4.0? pp. 231-234. Routledge.

[14] Gupta, M.S., Keen, M.M., Shah, M.A. \& Verdier, M.G. (2017). Digital Revolutions in Public Finance. International Monetary Fund.

[15] Booch, G., Rumbaugh, J. \& Jacobson, I. (2005). The Unified Modeling Language User Guide. ISBN-10: 0321-26797-4. ISBN-13, 978-0.

[16] Fettke, P. \& Loos, P. (2007). Perspectives on Reference Modeling. Reference Modeling for Business Systems Analysis, pp. 1-21. IGI Global.

[17] Wieringa, R.J. (2014). Design Science Methodology for Information Systems and Software Engineering. Springer.

[18] Deng, Q., Wang, Y. \& Ji, S. (2017). Design Science Research in Information Systems: A Systematic Literature Review 2001-2015.
[19] Johannesson, P., \& Perjons, E. (2014). An Introduction to Design Science. Springer.

[20] Kogan, A., Mayhew, B.W. \& Vasarhelyi, M.A. (2019). Audit Data Analytics Research-An Application of Design Science Methodology. Accounting Horizons, Vol. 33(3), pp. 69-73.

[21] Uppström, E. (2017). Designing, Theorizing, and Reflecting on Information Systems Artifacts and Value Co-creation in E-government.

[22] Vaishnavi, V., Kuechler, W. \& Petter, S. (2004). Design Science Research in Snformation Systems.

[23] Dresch, A., Lacerda, D.P. \& Miguel, P.A.C. (2015). A Distinctive Analysis of Case Study, Action Research and Design Science Research. Revista Brasileira de Gestão de Negócios, Vol. 17, pp. 1116-1133.

[24] DJA. (2014). Dasar-Dasar Praktek Penyusunan APBN di Indonesia. Direktorat Jenderal Anggaran

[25] Lee, D.K.P. (2017). Introduction to Python Data Analytics [Day 1].

[26] Davenport, T.H. (2013). What Do We Talk About When We Talk About Analytics? Enterprise Analytics, Optimize Performance, Process and Decision Through Big Data, pp. 9-18.

[27] Power, D., Heavin, C., McDermott, J. \& Daly, M. (2018). Defining Business Analytics: An Empirical Approach. Journal of Business Analytics, Vol. 1(1), pp. 40-53.

[28] Richardson, V.J., Teeter, R.A. \& Terrell, K.L. (2019). Data Analytics for Accounting. McGraw-Hill Education.

[29] Cantor, M. (2011). Object-oriented Project Management with UML.

[30] Chonoles, M.J. \& Schardt, J. A. (2011). UML 2 for Dummies. John Wiley \& Sons.

[31] Iivari, J. \& Venable, J.R. (2009). Action Research and Design Science Research-Seemingly Similar But Decisively Dissimilar.

[32] Hevner, A.R., March, S.T., Park, J. \& Ram, S. (2004). Design Science in Information Systems Research. MIS Quarterly, pp. 75-105.

[33] March, S.T. \& Smith, G.F. (1995). Design and Natural Science Research on Information Technology. Decision Support Systems, Vol. 15(4), pp. 251-266.

[34] Brendel, A.B., Zapadka, P. \& Kolbe, L. (2018). Design Science Research in Green IS-Analyzing the Past to Guide Future Research.

[35] Uliansyah, B. (n.d.). Automasi Data Dasar. https://github.com/BetaUliansyah/automasi-datadasar/

[36] Belim, S., Brechka, D., Gorbunova, T., Schmidt, I. \& Larionov, I. (2016). Data Mining Based on an Archaeological Geoinformation System ArGIS, pp. 14.

[37] Gaffney, V. \& Stancic, Z. (1991). GIS Approaches to Regional Analysis: A Case Study of the Island of Hvar. 